\title{
Educação em (Des)Construção: uma abordagem sobre o uso do ensino remoto nas
}

\section{universidades brasileiras}

\author{
Education in (De)Construction: an approach on the use of remote education in brazilian universities \\ Educación en (des) construcción: un enfoque sobre el uso de la educación a distancia en las
}

universidades brasileñas

Recebido: 18/01/2021 | Revisado: 20/01/2021 | Aceito: 22/01/2021 | Publicado: 30/01/2021

\author{
Eduardo Antero Premebida \\ ORCID: https://orcid.org/0000-0001-5852-4569 \\ Abracomex, Brasil \\ E-mail: Eduardopremebida8989@gmail.com
}

\begin{abstract}
Resumo
O ano de 2020 foi um marco na história mundial, como o ano em que precisamos nos isolar para conter o avanço da pandemia do COVID-19, nesse momento tivemos que reaprender a viver, e com isso aspectos culturais por todo o mundo foram de alguma forma afetada, o que parecia tão afastado da realidade tornou-se a melhor alternativa para as instituições de ensino para manter o setor operacionalizando. Nesse trabalho vamos abordar como as modalidades de ensino reagiram a tal impacto, e quais as expectativas para os próximos anos, analisando as experiencias dos alunos e professores de ensino superior. A pesquisa foi desenvolvida de forma bibliográfica e quantitativa, aliando a teoria aos dados obtidos a partir de dados coletados da pesquisa da Semesp, que contou com a participação de docentes e discentes de todo o Brasil. Vamos comparar a experiência dos docentes e dos discentes, sendo utilizado duas bases de dados, que foram obtidas entre os dias 6 e 15 de julho de 2020 , e 06 à 13 de julho de 2020, que contou com a participação de 413 professores e 2.588 estudantes de graduação, entre alunos matriculados, desistentes e concluintes. O questionário foi enviado por e-mail e também disponibilizado nas mídias sociais, tanto de instituições privadas como púbicas, de todo o Brasil. Nesse trabalho o objetivo foi abordar o comportamento dos alunos e professores com o formato de ensino remoto emergencial, quais os pontos fortes e onde é possível melhorar, e quais as perspectivas para o futuro.
\end{abstract}

Palavras-chave: Ensino remoto; EaD; Adaptação; Comportamento; COVID-19.

\begin{abstract}
The year 2020 was a milestone in world history, as the year in which we need to isolate ourselves to contain the progress of the COVID-19 pandemic. in some way affected, what seemed so far from reality has become the best alternative for educational institutions to keep the sector operational. In this work we will address how the teaching modalities reacted to such an impact, and what are the expectations for the coming years, analyzing the experiences of students and teachers of higher education. The research was developed in a bibliographic and quantitative way, combining theory with data obtained from data collected from Semesp's research, which counted on the participation of teachers and students from all over Brazil. We are going to compare the experience of teachers and students, using two databases, which were obtained between July 6 and 15, 2020, and July 6 to 13,2020, with the participation of 413 teachers and 2,588 undergraduate students, among enrolled students, dropouts and graduates. The questionnaire was sent by e-mail and also made available on social media, both from private and public institutions, from all over Brazil. In this work, the objective was to address the behavior of students and teachers in the format of emergency remote education, which are the strengths and where it is possible to improve, and which are the perspectives for the future.
\end{abstract}

Keywords: Remote teaching; Distance education; Adaptation; Behavior; COVID-19.

\section{Resumen}

El año 2020 fue un hito en la historia mundial, como el año en el que debemos aislarnos para contener el avance de la pandemia COVID-19, en ese momento tuvimos que reaprender a vivir, y con eso los aspectos culturales en todo el mundo estaban afectado de alguna manera, lo que parecía tan lejos de la realidad se ha convertido en la mejor alternativa para que las instituciones educativas mantengan operativo el sector. En este trabajo abordaremos cómo reaccionaron las modalidades docentes ante tal impacto, y cuáles son las expectativas para los próximos años, analizando las experiencias de estudiantes y docentes de educación superior. La investigación se desarrolló de manera bibliográfica y cuantitativa, combinando la 
teoría con los datos obtenidos de los datos recolectados de la investigación de Semesp, que contó con la participación de docentes y estudiantes de todo Brasil. Vamos a comparar la experiencia de docentes y alumnos, utilizando dos bases de datos, que se obtuvieron entre el 6 y el 15 de julio de 2020, y del 6 al 13 de julio de 2020, con la participación de 413 docentes y 2.588 estudiantes de pregrado, entre estudiantes matriculados, desertores y graduados. El cuestionario fue enviado por correo electrónico y también disponible en las redes sociales, tanto de instituciones públicas como privadas, de todo Brasil. En este trabajo, el objetivo fue abordar el comportamiento de estudiantes y docentes en el formato de educación remota de emergencia, cuáles son los puntos fuertes y donde es posible mejorar, y cuáles son las perspectivas de futuro.

Palabras clave: Enseñanza remota; Educación a distancia; Adaptación; Comportamiento; COVID-19.

\section{Introdução}

O ano de 2020 foi marcado pelo COVID-19, como o ano com muitas dificuldades, mas também uma oportunidade do mundo se reinventar, mudando hábitos e costumes. O vírus da categoria SARS-CoV-2, se espalhou pelo mundo rapidamente, deixando todos em alerta. Seu ponto inicial de contagio foi Wuhan, China, e em poucos meses afetou todo o mundo; em março, a OMS (Organização Mundial da Saúde) classificou a doença como pandemia mundial, nível mais alto de contágio. Por ser uma doença respiratória a circulação e a propagação do vírus são muito rápidas, o período de manifestação da doença é curto (podendo o hospedeiro manifestar sintomas de 2 a 14 dias após estar infectado).

Entre os sintomas mais comuns estão falta de ar, febre, tosse, dor de garganta, coriza entre outros; o método de prevenção e enfrentamento da doença são medidas de isolamento social, até que a população adquira uma imunização em massa, várias vacinas estão em fase de teste e aceitação, porem ações de conscientização da importância do distanciamento social são as ferramentas disponíveis para frear o avanço do contagio, foram feitas por todo o mundo, lockdown foi instaurado em locais com maior acumulo de pessoas. Somente no Brasil, o número de casos confirmados de 03 de janeiro de 2020 à 18 de janeiro de 2021, já chegou à 8.488.099 casos, e 209.847 mortes em todo o território, no mundo o número já chega a marca de 95.077.677 casos e 2.031.599 óbitos. Todos os setores, sem distinção, foram atingidos, e a educação não seria uma exceção, mas como fazer para manter o distanciamento necessário e assim mesmo não perder o ano letivo?

Com base no material coletado, vamos explanar sobre as diferenças do ensino remoto e do ensino a distância no Brasil, e quais as tendências e considerações a serem feitas, caso a doença venha se estender no ano letivo de 2021.

\section{Metodologia}

O artigo tem a característica de ser qualitativo e quantitativo, onde também é feita a busca verificar os aspectos emocionais e comportamentais, essa metodologia abrange a coleta de dados para tabular e expor em forma de gráficos as alternativas mais viáveis para um momento tão delicado, tanto dos discentes e docentes, com é o caso de pandemia. Muitas vezes os métodos qualitativos podem se transformar em quantitativos por meio do emprego de questões fechadas, por exemplo, pelo emprego da Escala Likert (Pereira A.S. et al., 2018, p. 67). Conforme Yin (2015) que é uma das maiores autoridades mundiais, em relação ao estudo de caso, considera que os métodos qualitativos e quantitativos não se excluem e podem ser importantes se complementando e permitindo um melhor entendimento dos fenômenos em estudo (citado por Pereira A.S. et al., 2018, p.69).

\section{Sistema Emergencial de Ensino (ERT)}

No Brasil, em todos os estados há suspensão de aulas para conter o avanço da pandemia do novo coronavírus. No mundo, de acordo com os últimos dados da Organização das Nações Unidas para a Educação, a Ciência e a Cultura (Unesco), que monitora os impactos da pandemia na educação, 191 países determinaram o fechamento de escolas e universidades (MEC, 2020). O ensino 
Research, Society and Development, v. 10, n. 1, e52410112063, 2021

(CC BY 4.0) | ISSN 2525-3409 | DOI: http://dx.doi.org/10.33448/rsd-v10i1.12063

remoto foi a opção mais viável para o momento delicado em que o mundo passa, porém, para muitos esse método é considerado similar a educação a distância, nesse tópico vamos expor as diferenças dos sistemas, e quais os pontos que permitem essa ambiguidade.

Para Hodges et al (2020, p.6), tradução do autor:

O ensino remoto de emergência (ERT) é uma mudança temporária de ensino para um modo de ensino alternativo devido a circunstâncias de crise. Envolve o uso de soluções de ensino totalmente remotas para instrução ou educação que, de outra forma, seriam ministradas presencialmente ou como cursos combinados ou híbridos e que retornariam a esse formato assim que a crise ou emergência diminuísse. O objetivo principal nessas circunstâncias não é recriar um ecossistema educacional robusto, mas, sim, fornece acesso temporário à instrução e suporte educacional de uma maneira que seja rápida de configurar e esteja disponível de forma confiável durante uma emergência ou crise.

As Estratégias de Aprendizagem Remota (EAR) são estruturações de possibilidades de atuação emergenciais para garantir educação não-presencial no cenário de pandemia, tendo como objetivo dar suporte ao gestor de educação para tomada rápida de decisão. (CIEB, 2020, p. 9). O ensino remoto permite o uso de plataformas já disponíveis e abertas para outros fins, que não sejam estritamente os educacionais, assim como a inserção de ferramentas auxiliares e a introdução de práticas inovadoras. (Garcia, 2020, p. 5)

O sistema educacional teve que ser realinhado de um dia para o outro, os professores precisaram adaptar suas aulas presenciais para plataformas on-line com o emprego das Tecnologias Digitais da Informação e Comunicação, sem preparação para isso, ou com preparação superficial, em caráter emergencial. Mesmo com vários problemas estruturais e formação deficitária na área tecnológica. (Rondini, 2020)

A pesquisa do Semesp, teve participação de 459 instituições diferentes, entre elas 343 privadas e 116 públicas. Desse total, $99,1 \%$ das privadas e $43,8 \%$ das públicas aderiram ao sistema remoto durante a pandemia, cerca de $84 \%$ e $81 \%$, respectivamente, concordaram que o ensino remoto se mostrou a melhor alternativa perante ao cenário de agravamento da doença. Quanto a opinião dos alunos, ao serem questionados sobre a experiencia das aulas remotas, temos o cenário: 
Research, Society and Development, v. 10, n. 1, e52410112063, 2021

(CC BY 4.0) | ISSN 2525-3409 | DOI: http://dx.doi.org/10.33448/rsd-v10i1.12063

Figura 1 - Fonte Semesp opinião dos alunos, página 13.

Com base na sua experiência, como você avalia:

"O modelo de aulas remotas adotado pela instituição foi o mais adequado para o

momento."

= Rede Privada = Rede Pública

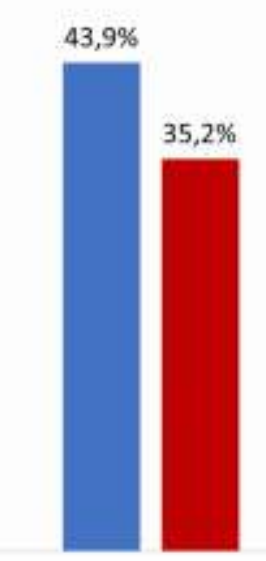

Concordo Totalmente

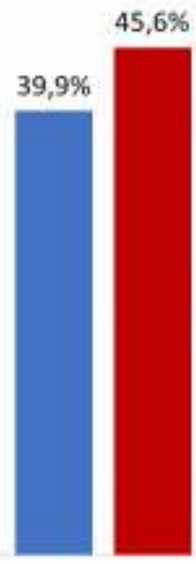

Concordo

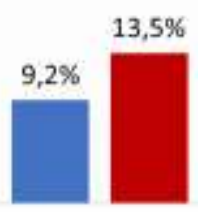

Discordo

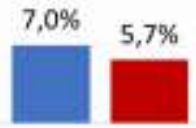

Discordo Totalmente

Fonte: Autor.

Quando o questionamento é para os professores, sobre se o modelo adotado para o momento pandêmico, os que discordam ou discordam totalmente não chega a 17\% dos entrevistados, ou seja, a aprovação do sistema tem mais aceitação do que rejeição. 
Figura 2 - Fonte Semesp opinião dos professores, página 8.
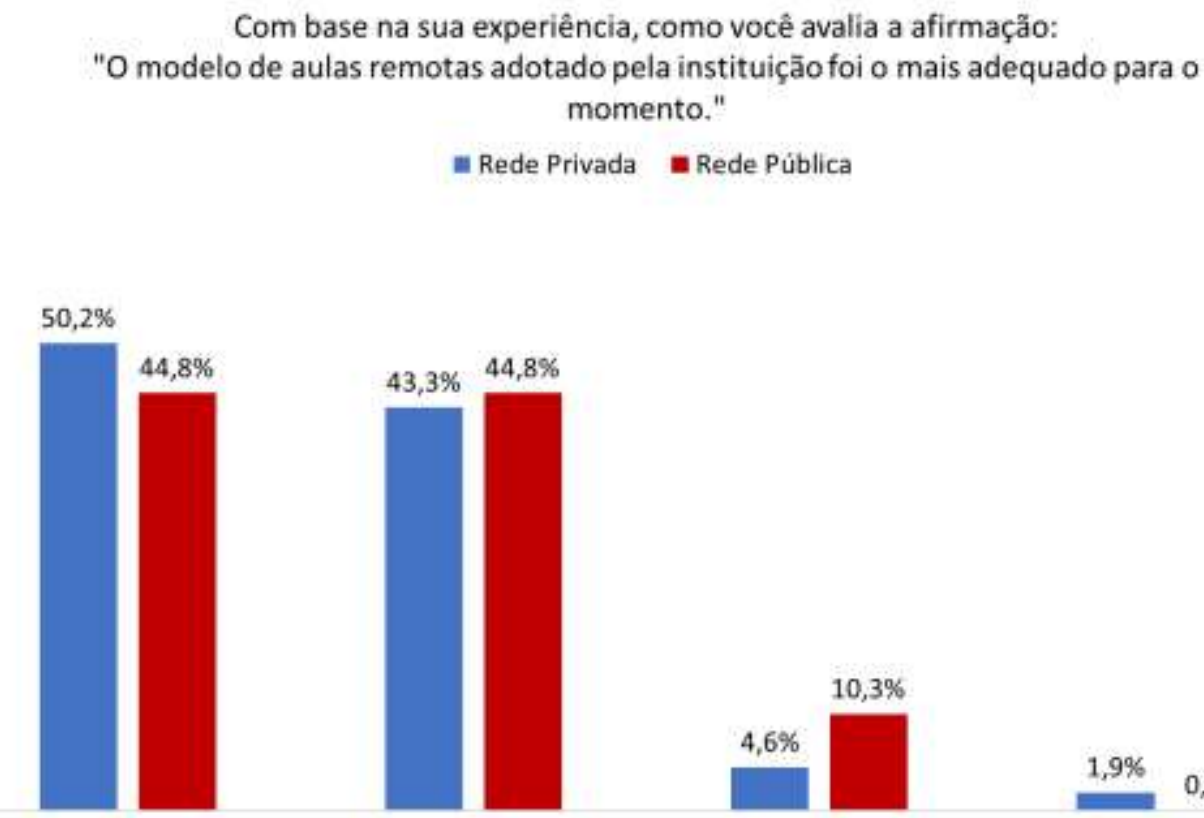

Concordo Totalmente

Concordo
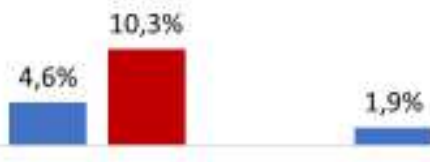

$0,0 \%$

Discordo

Discordo Totalmente

Fonte: Autor.

A diferença entre opiniões entre alunos e professores sobre o ensino remoto pode ser melhor exemplificado observando os gráficos, onde a aceitação desse formato acontece de forma mais expressiva por parte dos professores, sendo que apenas $6,5 \%$ da rede privada, e 10,3\% dos entrevistados discorda, ou discorda totalmente desse método de ensino; em contrapartida para os alunos a reprovação chega a 16,2\% na rede privada e 19,2\% na rede pública.

As maiores reclamações dos alunos estão na metodologia/didática das aulas, pois consideram cansativas e/ou pouco atrativas; demonstram falta de concentração o que faz ter maior resistência ao online; e problemas com a internet ou material disponibilizado.

Esse sistema exige um maior engajamento de alunos e de professores, para que haja uma melhor experiência e troca de informações, para GARCIA (2020, p.12): "O interesse do aluno é um aspecto desafiador para o ensino remoto, pois significa tornar a ambiência da apresentação das aulas tão ou mais atrativa do que aquilo que aluno encontrar disponível na rede.”

Já o conceito de Educação a Distância (EAD), é descrito no decreto número 2.494, de 10 de fevereiro de 1998, onde define:

Ensino que possibilita a auto-aprendizagem, com a mediação de recursos didáticos sistematicamente organizados, apresentados em diferentes suportes de informação, utilizados isoladamente ou combinados, e veiculados pelos diversos meios de comunicação. (...) com flexibilidade de requisitos para admissão, horário e duração, sem prejuízo, quando for o caso, dos objetivos e das diretrizes curriculares fixadas nacionalmente. 
As diferenças do sistema remoto e do ensino a distância, pode ser melhor exemplificado conforme quadro abaixo:

\begin{tabular}{|l|l|}
\hline Ensino remoto emergencial & EAD \\
\hline $\begin{array}{l}\text { Medida extraordinária para continuar a transmitir } \\
\text { o conteúdo e encontrar o aluno por meio das } \\
\text { plataformas digitais. }\end{array}$ & Possui uma metodologia de ensino. \\
\hline $\begin{array}{l}\text { Aulas ao vivo ou gravada nos dias e horário do } \\
\text { ensino presencial. }\end{array}$ & Videoaulas. \\
\hline Materiais adaptados pelo professor da turma. & $\begin{array}{l}\text { Materiais padronizados, elaborados e desenhados } \\
\text { por uma equipe especializada }\end{array}$ \\
\hline Interação com o professor da turma/disciplina. & Interação com professor tutor. \\
\hline Atividades mais síncronas. & Atividades mais síncronas e assíncronas. \\
\hline Calendário flexível. & Calendário padronizado. \\
\hline Avaliações adaptadas e centradas nas aulas. & Avaliações padronizadas. \\
\hline
\end{tabular}

Quadro adaptado pelo autor, disponível em: <https://www.linkedin.com/feed/update/urn:li:activity:6679396866687422464/>

Em ambos os sistemas existem aulas síncronas e assíncronas, que são aulas dirigidas pelo tutor da matéria, adequadas a cada necessidade, mas qual é a realidade e a expectativa delas.

A maior parte dos alunos entrevistados está acostumado com o sistema presencial, onde pode-se estar fisicamente próximo de um aluno e estar psicológica e pedagogicamente muito distante dele. Por outro lado, nas aulas virtuais é possível estar geograficamente distante e estar muito próximo psicológica e pedagogicamente, o que nos remete à ideia de motivar sempre a presença social. (Behar, 2020)

O ensino nas modalidades virtuais, desencadeiam a solidão no aluno, que por vezes sente-se desmotivado pela necessidade de interação, atenção e apoio por parte dos docentes. Essa insatisfação pode ser devido ao desapontamento pela falta da relação que o modelo presencial entre professor/aluno e entre colegas de turma proporciona. (Dosea et al, 2020)

Os professores foram pegos desprevenidos, e despreparados, porém muitos tiveram êxito, e até pretendem aderir ao sistema remoto mesmo depois da volta as aulas presenciais, as razões são simples, além de terem feito a adaptação das aulas, esse sistema permite uma troca de experiencia com outros docentes, a flexibilização de horários, redução de tempo de deslocamento e transporte, além da possibilidade de deixar as aulas gravadas, o que aumenta o engajamento do aluno, pois a aula pode ser assistida mais tarde caso tenha ficado alguma dúvida na explanação.

Os alunos quando perguntados sobre alternativas para melhorias deram várias opções que podem ajudar a viabilizar ações futuras, como criar um canal de apoio virtual para os estudantes acessar para sanar duvidas, melhorar a comunicação com o corpo docente, mudar a forma de avaliação, entre outras ideias de melhoria, quando questionado sobre o período pós pandêmico, 21,7\% dos alunos entrevistados gostariam de que o sistema seja hibrido, ou seja, participação presencial e a remota em momentos diversos do curso. 
Figura 3 - Fonte Semesp opinião dos alunos, página 22.

\section{Baseado na sua experiência com as aulas remotas, após o fim da restrição devido a pandemia, você: \\ = Rede Privada Rede Pública}

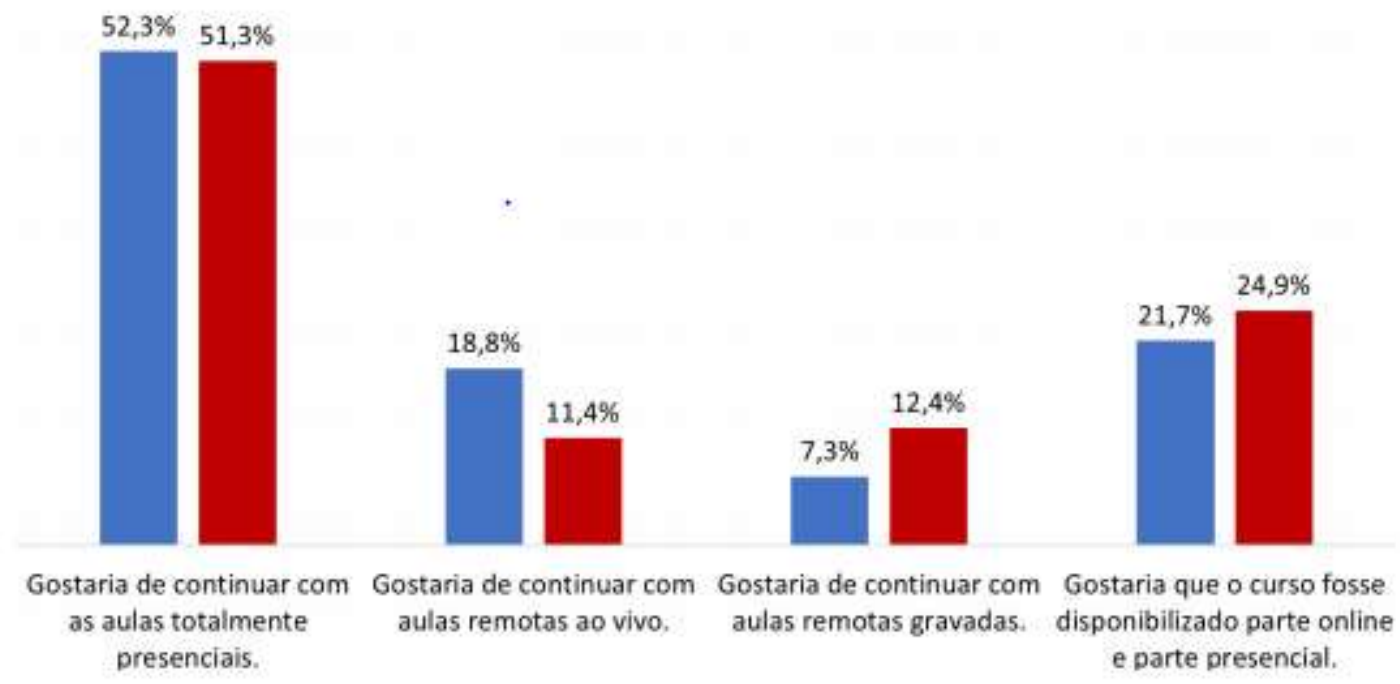

Fonte: Autor.

Conforme parecer do MEC (2020), número 11, aprovado em 07 de julho: "O retorno às atividades presenciais é bastante complexo e requer um planejamento detalhado. Ainda não há estudos para medir o impacto do fechamento provisório das escolas."

Em 10 de dezembro, o ministro da educação homologou o parecer 19/2020, onde permite que as aulas do ano de 2021 permaneçam no modelo não presencial, essa medida foi adotada para as instituições de ensino possam reorganizar seus calendários, replanejando os currículos, a volta as aulas no sistema presencial deve ocorrer de forma gradual, seguindo os protocolos de higiene e distanciamento físico entre estudantes, funcionários e profissionais, uma das alternativas sugeridas para o retorno presencial é fornecer um sistema de escalonamento na entrada e saída, instituições que obedecerem as normas de biossegurança podem ter o retorno antecipado, o governo prevê que a partir de 01 de março já devem ocorrer retornos graduais nas universidades e institutos federais.

A vacinação já começou em alguns países no final do ano de 2020, no dia 17 de janeiro de 2021, a Anvisa liberou o uso emergencial de vacinas no território nacional, com a primeira pessoa sendo vacinada no estado de São Paulo, existe um cronograma de 6 milhões de doses a serem fornecidas pelo Instituto Butantan, a parceria entre o Butantan e o laboratório da China é desenvolvida desde o dia 10 de junho de 2020. Em outubro do ano passado, foi divulgado que a Coronavac é a mais segura entre todas as vacinas testadas no Brasil. A retomada da vida como era antes deve ocorrer efetivamente depois da imunização da população, segundo a OMS (2020) "Grandes estudos de resultados de eficácia e segurança de 5 vacinas candidatas, incluindo esses três (e para Moderna e AstraZeneca), foram relatados publicamente por meio de comunicados à imprensa, mas apenas um (AstraZeneca) publicou resultados na literatura revisada por pares”. Segundo Ghebreyesus(2021), Diretor Geral da OMS, um ano após a publicação da OMS de seu primeiro relatório Disease Outbreak News sobre este vírus, mais de 30 países começaram a vacinar suas populações de alto risco com várias vacinas COVID-19. O governo brasileiro prevê uma vacinação em 4 etapas, dando prioridade a pessoas de mais 
idade(acima de 75 anos), para essa etapa estão previstas quase 14 milhões de doses; a segunda fase será para pessoas acima de 60 anos, em torno de 20 milhões de doses; na terceira fase serão atendidas pessoas com doenças que podem ser agravadas por conta da COVID-19, a quantidade de vacinas destinadas para esse grupo são 12.66 milhões; e na última fase estão previstos profissionais da educação, profissionais de sistema prisional e população particular, para essa fase estão previstas em média 3.5 milhões de vacinas.

No ano de 2021 teremos em torno de 50 milhões de pessoas imunizadas no Brasil, porém o número de habitantes segundo IBGE é de 212,5 milhões, com isso o que podemos esperar é que o ano de 2021, possivelmente todo o ano letivo, continuaremos com ensino não presencial, até que um número maior de pessoas possa ser imunizado.

\section{Considerações Finais}

Com o avanço dos métodos de contenção do vírus em pouco tempo voltaremos a ter uma maior interação, possivelmente com medidas de biossegurança, mas não com as aulas no sistema presencial anterior, para Alessandra Seixas quando questionada sobre a dinâmica do ensino, afirmou que: "O ensino inclusivo sempre foi desafiador porque é necessário todo um planejamento estratégico. E a pandemia veio e mostrou as fragilidades que nós já tínhamos, nós tivemos que nos apropriar de recursos que não tínhamos antes. Então, também para o ensino inclusivo houve um salto em modos de como lidar com esses alunos" (Hardt, 2021). Nessa perspectiva tivemos a experiência de um ano em ensino remoto, o que proporcionou acesso a novas tecnologias, e com ela uma gama de novas possibilidades se formou, dando espaço a um sistema antes sem visibilidade.

Ao longo desse trabalho conseguimos reconhecer as divergências e convergências do sistema remoto e EaD, como também foram feitas sugestões para melhoria do ensino, como a possibilidade de um sistema misto de ensino depois do período pandêmico. Um novo estudo pode ser disponibilizado no futuro, observando os fatores, vantagens e desvantagens de um sistema hibrido de ensino, onde o autor pode verificar o impacto da migração de sistemas, e quais os aspectos culturais e comportamentais que estaríamos mudando com a implantação de um projeto piloto.

Para que isso ocorra, alguns tramites teriam que ser aprovados pelo Ministério da Educação, junto com o governo federal, para que além da matriz curricular haja um incentivo para a formação e migração do ensino presencial para uma modalidade hibrida de ensino, como defende o especialista em ensino Renato Casagrande que as aulas presenciais e não presenciais, com certeza, serão o modelo em 2021. Por isso, teremos a implantação praticamente em todo o sistema educacional nacional brasileiro (Hardt, 2021).

Para futuros trabalhos podem ser explorados aspectos comportamentais, culturais e psicológicos da metodologia adotada ao longo dos cursos de graduação, tendo em vista a diferença didática dos sistemas de ensino em diferentes áreas de formação, e o impacto em diferentes faixas etárias.

\section{Referências}

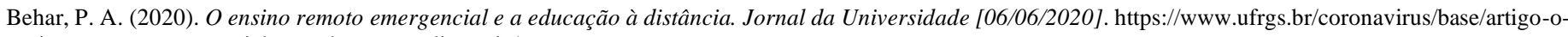
ensino-remoto-emergencial-e-a-educacao-a-distancia/.

Saldanha, L. C. D. (2020). O discurso do ensino remoto durante a pandemia de COVID-19. Revista Educação e Cultura Contemporânea, 17(50), 124-144.

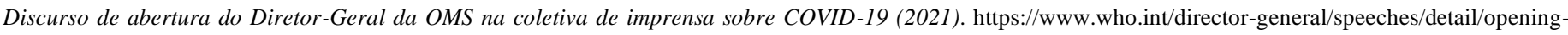
remarks-for-the-media-briefing-on-covid-19-5-january-2021.

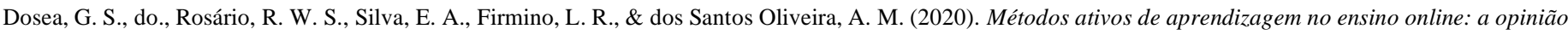
de universitários durante a pandemia de COVID-19. Interfaces Científicas-Educação, 10(1), 137-148.

Informativa COVID, F. (2020). 19-Escritório da OPAS e da OMS no Brasil. Organização Pan-Americana da Saúde. 
Research, Society and Development, v. 10, n. 1, e52410112063, 2021

(CC BY 4.0) | ISSN 2525-3409 | DOI: http://dx.doi.org/10.33448/rsd-v10i1.12063

Garcia, T. C. M., Morais, I. R. D., Zaros, L. G., \& Rêgo, M. C. F. D. (2020). Ensino remoto emergencial: proposta de design para organização de aulas. Natal.

SEDIS/UFRN. $17 \quad$ p.: $\quad$ il. https://repositorio.ufrn.br/bitstream/123456789/29767/1/ENSINO\%20REMOTO\%20EMERGENCIAL_proposta_de_design_organizacao_aulas.pdf

Google notícias (2021). https://news.google.com/covid19/map?hl=pt-BR\&gl=BR\&ceid=BR\%3Apt-419.

Hardt, C. Pandemia acelera o ensino híbrido na educação brasileira e cria desafios para 2021 (2021). https://jovempan.com.br/noticias/brasil/pandemia-acelera-oensino-hibrido-na-educacao-brasileira-e-cria-desafios-para-2021.html?amp.

Hodges, C., Moore, S., Lockee, B., Trust, T., \& Bond, A. (2020). The difference between emergency remote teaching and online learning. Educause Review, 27.

Instituto Semesp (2020). Pesquisa Adoção de Aulas Remotas | Visão do professor. Edição Final.

Instituto Semesp (2020). Pesquisa Adoção de Aulas Remotas | Visão dos alunos. Edição Final.

Joye, C. R., Moreira, M. M., \& Rocha, S. S. D. (2020). Educação a Distância ou Atividade Educacional Remota Emergencial: em busca do elo perdido da educação escolar em tempos de COVID-19. Research, Society and Development, 9(7), e521974299-e521974299.

Lima, E. S., \& Junior, J. B. B. (2015). Revisão Sistemática da Literatura: as causas da evasão nos cursos de Graduação a Distância/Systematic Literature Review: the evasion causes in undergraduate distance courses. Revista EducaOnline, 9(3), 32-69.

Ministério Da Educação Conselho Nacional De $\quad$ Educação. http://portal.mec.gov.br/index.php?option=com_docman\&view=download\&alias=167131-pcp019-20\&category_slug=dezembro-2020-pdf\&Itemid=30192.

Ministério da Educação. (2020). CNE aprova diretrizes para escolas durante a pandemia. http//portal.mec.gov.br/busca-gera//12-noticias/acoes-programas-e-projetos-637152388/89051-cne-aprovadiretrizes-para-escolas-durante-a-pandemia

Pereira A. S. et al. (2018). Metodologia da pesquisa científica. [e-book]. Santa Maria. Ed. UAB/NTE/UFSM. https://repositorio.ufsm.br/bitstream/handle/1/15824/Lic_Computacao_Metodologia-Pesquisa-Cientifica.pdf?sequence=1

Projeção da população - IBGE (202lhttps://www.ibge.gov.br/apps/populacao/projecao/box_popclock.php.

Revista Veja Saúde (2020). Como é o plano de vacinação contra a Covid-19 do governo federal. https://saude.abril.com.br/medicina/como-e-o-plano-de-vacinacaocontra-a-covid-19-do-governo-federal/.

Rondini, C. A., Pedro, K. M., \& dos Santos Duarte, C. (2020). Pandemia do Covid-19 e o ensino remoto emergencial: Mudanças na práxis docente. Interfaces Científicas-Educação, 10(1), 41-57.

Sabóia, G., Mazieiro, G., Andrade, H. de., \& Adorno, L. Anvisa aprova uso emergencial das vacinas CoronaVac e AstraZeneca no Brasil (2021). https://noticias.uol.com.br/saude/ultimas-noticias/redacao/2021/01/17/anvisa-aprova-pedido-de-vacina-do-butantan-e-da-fiocruz.htm

Vilela, P. R (2020). Governo entrega ao STF plano nacional de vacinação contra a covid-19. https://agenciabrasil.ebc.com.br/saude/noticia/2020-12/governoentrega-ao-stf-plano-nacional-de-vacinacao-contra-covid-19.

World Health Organizacion: Brasil (2021). https://covid19.who.int/region/amro/country/br. 